\title{
Growth Failure of Unknown Etiology
}

National Cancer Institute

\section{Source}

National Cancer Institute. Growth Failure of Unknown Etiology. NCI Thesaurus. Code C118469.

Subnormal linear growth rate in an infant, child or adolescent based on the normative values for the age and sex of the reference population; the cause of the growth failure is unknown. 